\title{
OS DIREITOS INDIVIDUAIS E A REVISÃO DO DIREITO PRÉ- CONSTITUCIONAL BRASILEIRO EM SEDE DE CONTROLE CONCENTRADO DE CONSTITUCIONALIDADE
}

\author{
INDIVIDUAL RIGHTS AND THE REVIEW OF BRAZILIAN PRE- \\ CONSTITUTIONAL LAW IN THE SCOPE OF CONCENTRATED \\ CONSTITUTIONAL REVIEW
}

Teresinha Inês Teles Pires ${ }^{*}$

\begin{abstract}
RESUMO: o presente artigo investiga a aplicação das modernas técnicas de exercício do controle concentrado de constitucionalidade no sistema brasileiro, no tocante às leis e atos normativos anteriores à Constituição em vigor. Será mostrado o percurso por meio do qual foi construída, perante o Supremo Tribunal Federal, a admissibilidade do controle de constitucionalidade do direito pré-constitucional, e como a modulação dos mecanismos de revisão judicial trouxe para a prática decisória uma notória e produtiva flexibilidade procedimental. A interpretação conforme a constituição, particularmente, aperfeiçoa-se enquanto um instrumento destinado à preservação das normas legais não totalmente inconstitucionais, além de possibilitar a necessária extirpação, do ordenamento jurídico, de hipóteses de aplicação das leis que se mostrem desconformes ao estatuto principiológico dos dispositivos da Constituição. Na mesma direção, o instituto da Arguição de Descumprimento de Preceito Fundamental tem se mostrado uma importante via para a defesa da supremacia da Constituição e da efetivação das liberdades individuais nela asseguradas.
\end{abstract}

PALAVRAS-CHAVE: Controle concentrado. Descumprimento de preceito fundamental. Direito pré-constitucional. Interpretação constitucional. Jurisdição constitucional.

ABSTRACT: This paper investigates the updated techniques regarding the exercising of the concentrated control of constitutionality in the Brazilian system, on laws and norms enacted prior to the current Constitution. It will be shown how was built the admissibility of preconstitutional law review in the Supreme Court, and how the modulation mechanisms of judicial review brought a remarkable, productive procedural flexibility to the decision-making practice. The interpretation according to the constitution, particularly, is being improved as an instrument for the preservation of legal norms which are not entirely unconstitutional. Besides, it enables the necessary removal, from the legal system, of hypotheses that are deemed nonconforming to the principle-based constitutional provisions. In the same direction, the instrument called Claim of Breach of Fundamental Precept has been an important mean for the defense of the Constitution supremacy and for the effectiveness of individual freedoms therein guaranteed.

KEYWORDS: Breach of fundamental precept. Concentrated control. Constitutional interpretation. Constitutional jurisdiction. Pre-constitutional law.

\footnotetext{
* Graduada em Direito pela Universidade Federal de Goiás (1987), mestre em Filosofia pela Universidade Federal do Rio Grande do Sul (1994) e doutoranda em Direito pelo Centro Universitário de Brasília - UniCEUB. Promotora de justiça do Ministério Público do Distrito Federal e Territórios.
} 
Sumário: introdução. 1. A ampliação da Jurisdição Constitucional - as decisões interpretativas e os direitos individuais. 2. A problemática do Controle de Constitucionalidade das leis pré-constitucionais. 3. Aplicação da técnica da Interpretação conforme a Constituição ao direito pré-constitucional. 4. O cabimento da Ação de Descumprimento de Preceito Fundamental no controle de leis ou atos normativos. 5. Conclusão.

\section{INTRODUÇÃO}

Com o objetivo de contribuir para o estudo dos mecanismos processuais de exercício da Jurisdição Constitucional, o presente trabalho tentará refletir acerca das técnicas atuais de aplicação do direito em matéria de controle concentrado de constitucionalidade no Brasil, particularmente no tocante às leis e aos atos normativos anteriores à Constituição.

Buscar-se-á analisar a receptividade em nosso sistema judicial das decisões de natureza interpretativa, que envolvem certo grau de recriação do texto jurídico. O Supremo Tribunal Federal (STF) mostra-se comprometido com a valorização das expectativas pela concretização dos direitos individuais, ainda que isso possa implicar em uma crise institucional do ponto de vista da caracterização da função legislativa.

Será mostrado o percurso por meio do qual foi construída a admissibilidade do controle de constitucionalidade do direito pré-constitucional, e como a modulação das técnicas de revisão judicial trouxe para a prática decisória uma notória e produtiva flexibilidade procedimental.

Optou-se por destacar a validade da técnica da interpretação conforme a Constituição, haja vista que o STF vem aperfeiçoando sua utilização enquanto um instrumento destinado à preservação das normas legais não totalmente inconstitucionais. Esse mecanismo permite o alcance de um equilíbrio na distribuição das competências e, no mesmo passo, abre o caminho para a necessária extirpação, do ordenamento jurídico, de hipóteses de aplicação das leis que se mostrem desconformes ao estatuto principiológico dos dispositivos da Constituição.

Igual destaque será conferido à abordagem dos requisitos exigidos para o conhecimento da arguição de descumprimento de preceito fundamental (ADPF), importante via para a defesa da supremacia da Constituição e da efetivação das liberdades individuais nela asseguradas. Como se verá, especial enfoque se atribui às possibilidades de revisão judicial das leis anteriores à Constituição por meio da modalidade autônoma da ADPF 
(controle concentrado), considerando a dispensa de determinados pressupostos processuais, os quais são exigíveis somente para a interposição da arguição incidental.

\section{A AMPLIAÇÃO DA JURISDIÇÃO CONSTITUCIONAL - AS DECISÕES INTERPRETATIVAS E OS DIREITOS INDIVIDUAIS}

O debate jurídico acerca do crescimento da atuação do Poder Judiciário no exercício do controle de constitucionalidade é atualmente objeto das mais diversas ponderações, no que tange à legitimidade das chamadas decisões interpretativas ${ }^{1}$.

O florescimento da Jurisdição Constitucional adveio da necessidade de se firmar a supremacia da Constituição em relação ao sistema normativo infraconstitucional. Diante da moldura aberta dos preceitos fundamentais, o controle de constitucionalidade terminou gerando um conflito de competências no exercício dos poderes institucionais, e uma reformulação do princípio clássico da separação de poderes. A partir daí, reavivou-se a controvérsia em torno da atuação política da função jurisdicional ${ }^{2}$. Para algumas doutrinas, interpretação e criação do direito, na atividade judicante, tornaram-se atos substancialmente interligados (FALCONE, 2009; BARROSO, 2011), em vista da conexão do sentido da norma jurídica à realidade empírica na qual ela se insere.

No Brasil, como se sabe, o controle de constitucionalidade pode ser concentrado (abstrato) ou difuso (incidental). A Constituição de 1988 atribuiu grande ênfase ao modelo concentrado, passando "as questões constitucionais" "a ser veiculadas, fundamentalmente, mediante ação direta de inconstitucionalidade perante o Supremo Tribunal Federal." Posteriormente, introduziu-se "a ação declaratória de constitucionalidade" - Emenda Constitucional $n^{\circ}$ 3/1993 - e mais tarde a ação de descumprimento de preceito fundamental Lei 9882/1999 (MENDES, 2009, p. 209-10 e 216).

Dentro deste quadrante institucional, iniciou-se a compreensão interpretativa das decisões judiciais de uma forma mais abrangente e não exclusivamente centrada na literalidade do arcabouço legal. A configuração da natureza dessas decisões se deve

\footnotetext{
${ }^{1}$ Entendidas como decisões que não conduzem propriamente à "pronúncia de inconstitucionalidade"; essas decisões preservam o dispositivo legal questionado delimitando uma interpretação específica para a admissão de sua validade. Podem consistir na fixação de um ou mais significados do texto "que sejam compatíveis com a Constituição" ou na exclusão de "um ou mais significados com ela incompatíveis" (COLNAGO, 2007, p. 19 e 67).

${ }^{2}$ Sobre o processo de judicialização da política no Brasil, cf. VIANNA, 1999, p. 47-70; BARROSO, 2011, p. 379-404; e STRECK, 2004, p. 179-96, que apresenta salutar justificativa para que o poder judiciário adote uma atitude ativa na "implementação de políticas públicas" e na "correição de prestações dos serviços sociais básicos" (op. cit., p. 186).
} 
basicamente à imposição ao Poder Judiciário da tarefa de solucionar os conflitos existentes entre as expectativas sociais de reconhecimento de direitos e a ação ou omissão do Estado. O poder interpretativo é dotado de bilateralidade, na medida em que se refere "tanto à norma constitucional como à lei que se coloca como contraponto ao texto constitucional" (STRECK, 2004, p. 841-2). A Corte Constitucional brasileira vem amadurecendo cada vez mais sua atuação no exame da correspondência dos textos produzidos pelo legislador aos ditames da Constituição vigente, embora o avanço nesse campo esteja ainda muito distante de um nível suficiente para fazer frente ao não cumprimento efetivo de diversos princípios constitucionais. Como enfatizado por Lenio Streck (2004, p. 846), no Brasil valoriza-se mais o direito infraconstitucional que o constitucional. É o que ele denomina de "baixa constitucionalidade".

Parte da doutrina internacional, dedicada ao estudo dos métodos de aplicação do direito, defende a necessidade da utilização de estratégias argumentativas para a "justificação das decisões judiciais". Esse pensamento se apoia nas correntes "não-interpretativistas", que legitimam o poder das cortes superiores na atualização dos "valores substantivos presentes na Constituição" a partir do conteúdo dos seus princípios gerais - políticos ou morais (SAMPAIO, 2002, p. 781) ${ }^{3}$. Na esteira de Ronald Dworkin (2006), o controle jurisdicional de constitucionalidade promove a filtragem dos comandos normativos e a extensão do rol dos direitos fundamentais, sendo concebido como o estágio final da aplicação da lei. Em outras palavras, a produção, por parte da atividade interpretativa, de novos direitos não expressamente previstos na Constituição, desenvolve-se em um cenário de reinvenção das tradições culturais (ROSENFELD, 2010), em que se procura adequar as normas jurídicas às mudanças ocorridas nos fatos e nas demandas sociais, tomando-se por parâmetro a coerência com os precedentes judiciais.

No contexto brasileiro, a perspectiva da concretização das normas constitucionais se centra primordialmente na efetivação dos direitos fundamentais, sobretudo aqueles que se destinam a garantir as liberdades individuais ${ }^{4}$. A finalidade da ação do Judiciário no preenchimento das lacunas legais é promover a maximização da "eficácia" desses "direitos" (SARLET, 2007, p. 286), ou, no dizer de Adércio Sampaio (2002, p. 670), proceder à "estruturação" desses direitos. Sua aplicabilidade imediata, estabelecida no $\S 1^{\circ}$ do artigo $5^{\circ}$

\footnotetext{
${ }^{3}$ Para um aprofundamento das correntes interpretativistas e não-interpretativistas, desenvolvidas na dogmática norte-americana, cf. PERRY, 1994, p. 54 et seq., e ELY, 1980, p. 11 et seq. Cf. também CANOTILHO, 1999, p. 1121-4.

${ }^{4}$ Não serão especificados, para os propósitos do presente estudo, o significado distinto dos termos direitos, liberdades e garantias individuais. Entender-se-á que as três categorias configuram "um sistema unitário" voltado à ideia "de liberdade e de limitação do poder" (MIRANDA, 1993, p. 100). 
da Constituição Federal, aumentou significativamente a complexidade da interpretação jurídica, que passou a conter uma "dimensão política" preponderante. A atividade do intérprete pressupõe "uma leitura moral dos valores comunitários", além da consideração "dos dissensos das minorias" e de sua interferência na reconstrução do princípio democrático (CANOTILHO, 1999, p. 316-7, 1045 e 1068).

As liberdades individuais, concebidas como direitos subjetivos "de autonomia e de defesa" contra o Estado foram, a partir do século XX, inseridas na realidade do Estado Social, ou seja, não mais são definidas de forma estruturalmente isoladas. Exige-se, pelo princípio da igualdade, sua "harmonização" com "os direitos econômicos, sociais e culturais". De qualquer sorte, as liberdades individuais caracterizam-se pelo reconhecimento de uma "alternativa de comportamento", da "possibilidade de escolha de um comportamento" (CANOTILHO, p. 25, 47 e 1182), o que deve ser garantido às pessoas nos limites razoavelmente fixados em face da ordem objetiva institucional.

Nas palavras de Jorge Miranda (1993, p. 79, 86, 89 e 98), direitos individuais são "direitos fundamentais autônomos", sendo dotados de um "sentido de resistência ao poder", qualquer que seja sua espécie. Protege-se a "autodeterminação", o livre desenvolvimento "da personalidade moral e física" individual, o que envolve a escolha entre "agir e não agir". A defesa desses direitos pode impor abstenções ou ações aos entes estatais, de acordo com as circunstâncias do caso concreto.

Em sede de controle de constitucionalidade concentrado, instaura-se um processo de natureza objetiva (ausência de lide). Isso não quer dizer que esta espécie de controle se situa "apenas no campo teórico, sem referência ao mundo dos fatos". A apreciação de elementos da realidade empírica circundante compõe o campo da revisão judicial, inclusive no tocante à "prognose do legislador", que se refere a "fatos futuros" (TAVARES, 2001, p. 278-80). Sempre haverá um questionamento acerca de um direito individual nas ações levadas diretamente ao Supremo Tribunal Federal, o que torna o controle concentrado uma via profícua também na reivindicação desses direitos.

Contudo, o enfraquecimento do modelo difuso da judicial review dificulta o acesso dos cidadãos aos tribunais superiores, uma vez que a defesa dos direitos individuais por ação direta, interposta pelo próprio interessado, é vedada no sistema judicial brasileiro. Ao indivíduo é facultada a possibilidade da interposição de mandado de segurança, mas ele não é cabível "para combater lei em tese" (BRASIL, 1963). Existem ainda os remédios processuais específicos, para a proteção de determinados direitos, como o habeas-corpus, o habeas-data, a ação popular e a ação civil pública, os quais só chegam à Suprema Corte incidentalmente. 
$\mathrm{Na}$ ausência de um remédio específico, pode-se pensar no aperfeiçoamento de instrumentos institucionais aptos à proteção das liberdades individuais que se situem até mesmo no plano não jurisdicional. No Brasil, destaquem-se, nesse sentido, as prerrogativas conferidas ao Ministério Público, cuja atuação não raro "termina por desembocar nos tribunais ou juízes constitucionais" (SAMPAIO, 2002, p. 165, 171-4 e 176), e as políticas públicas desenvolvidas por órgãos administrativos, a exemplo das inúmeras medidas adotadas pelo Ministério da Saúde na prestação dos serviços médico-assistenciais ${ }^{5}$.

\section{A PROBlemÁtica do CONTROLE DE CONSTITUCIONALIDADE DAS LEIS PRÉ-CONSTITUCIONAIS}

À época da vigência das Constituições de 1967/1969 os conflitos entre "o direito préconstitucional" e a Constituição eram solucionados por meio dos "princípios de direito intertemporal". A Constituição de 1988 não definiu essa questão "expressamente", razão pela qual a jurisprudência do STF se firmou inicialmente de modo favorável à aplicação do direito intertemporal. A matéria foi apreciada na $\mathrm{ADI} \mathrm{n}^{\circ}$ 2, tendo o então relator, Ministro Paulo Brossard, arguido que "as leis anteriores à constituição" não poderiam ser reputadas inconstitucionais, simplesmente porque a Constituição ainda não existia à época em que aquelas foram elaboradas. Por isso, em se verificando sua incompatibilidade com a Constituição, a hipótese seria de revogação das leis pretéritas, e não o fenômeno da inconstitucionalidade (MENDES, 2011, p. 115 e 117-9; BARROSO, 2011, p. 204).

Com a evolução do debate chegou-se à constatação de que o princípio da revogação da lei anterior pela posterior não poderia aplicar-se às normas de "densidade normativa" diferenciada. Assim, passou-se a se entender que o princípio a prevalecer em matéria de conformidade do direito pré-constitucional à nova Constituição seria o da supremacia das normas constitucionais, legitimando-se o controle abstrato de matéria legislativa precedente. O assunto foi finalmente pacificado pela Lei 9882/1999, disciplinadora da "arguição de descumprimento de preceito fundamental" (ADPF), que estabeleceu (art. $1^{\circ}$, inciso I) "a possibilidade de exame", mediante revisão judicial, do direito pré-constitucional (MENDES, 2011, p. 122 e 124).

Como já havia pontuado o mestre Canotilho (1999, p. 1076 e 1104), as prescrições constitucionais determinam o próprio conteúdo das normas infraconstitucionais, ocorrendo, nessa conformação, a "conversão do direito ordinário em direito constitucional concretizado".

\footnotetext{
${ }^{5}$ Disponíveis para consulta em http://www.saude.gov.br.

Revista da Faculdade de Direito - UFPR, Curitiba, vol. 59, n. 3, p. 37-54, 2014.
} 
A "aplicabilidade direta" dos princípios constitucionais independe de sua "positivação legislativa", o que importa também na "inconstitucionalidade de todas as leis préconstitucionais" a eles contrapostas - "inconstitucionalidade superveniente".

A "fiscalização da legitimidade constitucional” do ordenamento jurídico anterior impõe "certo trabalho reconstrutivo" voltado para a definição das normas que não podem ser objeto de "recepção constitucional", em vista de seu antagonismo material com os novos valores introduzidos (SAMPAIO, 2002, p. 371-2). A rigor, todo o sistema normativo deveria ser objeto de reinterpretação à luz dos princípios constitucionais, especialmente no caso da Constituição brasileira, com seu extenso rol de direitos fundamentais. Considerando-se o lento trabalho legislativo, e a abrangência ainda insatisfatória dos mecanismos processuais de acesso ao controle de constitucionalidade, o sistema brasileiro convive com vetusto arcabouço legislativo carente de revisão. Veja-se, por exemplo, o caso do Código Penal, elaborado em 1940, e só agora objeto de projeto de reforma (PLS nº 236/2012), em trâmite no Congresso Nacional.

Acredita-se que a evolução das hipóteses de adequação do instituto da ADPF, que, como já dito, pode ser manejada para a revisão do direito pré-constitucional, promoverá o salutar amadurecimento reflexivo acerca de uma reforma legislativa mais abrangente, nos planos federal, estadual e municipal.

Quanto ao procedimento da ADPF, em sua aplicabilidade ao direito préconstitucional, Gilmar Mendes (2011, p. 269) salienta ser recomendável, em caso de procedência, que se declare a "inconstitucionalidade" (nulidade) da lei e também sua "ilegitimidade" "em face da nova ordem constitucional". Há também a possibilidade de a inconstitucionalidade ser declarada no que tange à aplicação da norma a grupo específico de pessoas ou a situações específicas. É a chamada "inconstitucionalidade parcial” "sem redução de texto". O Tribunal considera inconstitucional "determinada hipótese de aplicação da lei, sem proceder à alteração do seu programa normativo" (MENDES, 2011, p. 274). O controle de constitucionalidade vai adquirindo, assim, um contorno múltiplo, permitindo a modulação da validade da norma, de maneira a preservar sua legitimidade em geral, excepcionando-se apenas algumas hipóteses fáticas de ilegitimidade.

No caso de lei pré-constitucional, essa "flexibilização das técnicas" de controle de constitucionalidade apresenta "relevância ímpar" (MENDES, 2011, p. 300), por oportunizar o exame da conformidade do sistema legislativo ordinário com a nova ordem constitucional, sem necessariamente fulminar de nulidade todo o texto normativo questionado. No aspecto da segurança jurídica, uma concepção metodológica maleável tem a vantagem de viabilizar a 
atualização gradativa das leis infralegais, de acordo com a apresentação das reivindicações concretas de reconhecimento de direitos.

Outro enfoque em franca efervescência é o da delimitação do poder normativo do executivo "para fazer frente, em caráter de excepcionalidade, às demandas econômicas, sociais e até políticas”. Algumas correntes doutrinárias defendem que lei e regulamento são "atos da mesma natureza, comportando o mesmo conteúdo". No Brasil, em regra, criam-se "direitos e obrigações" por meio de leis, mas já se admite, em nossa "prática constitucional", algum nível de discricionariedade e livre disposição "do conteúdo desses direitos e obrigações por norma infralegal" (SAMPAIO, 2002, p. 446, 458-9 e 462).

Em síntese, a jurisprudência constitucional e as políticas públicas administrativas, numa perspectiva de colaboração com a reconstrução do sistema legislativo, caminham juntas na busca da efetivação dos direitos individuais e sociais constitucionalmente assegurados. A Constituição de 1988 delega aos demais poderes estatais a faculdade de criar, através de seus órgãos responsáveis pela concretização dos princípios fundamentais, novos direitos deles derivados ou derivados de "tratados internacionais" ratificados (BRASIL, 1988, art. $5^{\circ}, \S 2^{\circ}$ ). No que concerne ao direito pré-constitucional, ainda mais frutífera pode ser essa delegação, por permitir a atualização do conteúdo das leis levando-se em conta o estágio corrente de informação científica e os dados gerais da realidade sociopolítica.

\section{APLICAÇÃO DA TÉCNICA DA INTERPRETAÇÃO CONFORME A CONSTITUIÇÃO AO DIREITO PRÉ-CONSTITUCIONAL}

A interpretação conforme a Constituição consiste em uma técnica de revisão de norma infraconstitucional cada vez mais recepcionada na prática decisória do Supremo Tribunal Federal. Trata-se de um modelo de decisão interpretativa fundamentado nos "princípios do máximo aproveitamento" das leis e da "harmonia entre os Poderes" institucionais, com o objetivo de assegurar a supremacia da Constituição sem a pronúncia de inconstitucionalidade. Outro propósito perseguido pela medida é o da limitação da atuação judiciária (COLNAGO, 2007, p. 94 e 131).

A Lei 9868/1999 (BRASIL, 1999), que disciplina as ações diretas de inconstitucionalidade e de constitucionalidade, prevê, em seu artigo 27, a discricionariedade do Supremo Tribunal para, por maioria absoluta, "restringir os efeitos" da respectiva declaração. Quer dizer, o poder de proferir decisões interpretativas passou a ser expressamente conferido, em sede de jurisdição constitucional, pela mencionada lei. 
Por meio da interpretação conforme a Constituição, o Supremo define que a lei examinada não é inconstitucional, desde que interpretada de uma forma determinada. A partir do julgado, as demais interpretações tornam-se ilegítimas ${ }^{6}$. Exige-se, para o manejo da técnica, a existência de mais de uma interpretação possível. Neste aspecto, o critério hermenêutico adotado visa eliminar a ambivalência acerca do significado da lei, normalmente restringindo seu campo de aplicação. Não raro, o Supremo reputa configurada a inconstitucionalidade mesmo quando as restrições que delimita não estão expressamente estabelecidas na Constituição. É o que ocorre, por exemplo, na hipótese de se verificar a incompatibilidade entre a lei questionada e os princípios constitucionais abstratos ${ }^{7}$.

Discute-se a similaridade observada entre a interpretação conforme a Constituição e outra técnica hermenêutica denominada "declaração de nulidade" (parcial) "sem redução de texto". Costuma-se distinguir as duas técnicas da seguinte maneira: por meio da interpretação pela conformidade, declara-se a constitucionalidade da lei "com a interpretação que lhe é conferida pelo órgão judicial"; por meio da nulidade parcial, declara-se a inconstitucionalidade "de determinadas hipóteses de aplicação" da lei sem modificação do texto (MENDES, 1996, p. 275). Não há, porém, um consenso a respeito das reais distinções entre os dois métodos quanto aos seus resultados práticos ${ }^{8}$. Na maioria das decisões, o Supremo promove, por meio da interpretação pela conformidade, a exclusão de uma ou mais hipóteses de aplicação da norma sem redução de texto, declarando a inconstitucionalidade dessa aplicação, o que gera os mesmos efeitos da declaração de nulidade parcial. Dogmaticamente é importante diferenciar os dois institutos; mas, no Brasil, até o momento, não se dá relevância a essa diferenciação no exercício da jurisdição constitucional.

Em tese, a interpretação pela conformidade tem seus limites estabelecidos pelo critério da não admissão da criação de uma nova norma distinta e desvinculada do texto produzido pelo legislador. Do contrário, o intérprete estaria substituindo a conformação legislativa atribuída à matéria. A exigência de que a norma seja passível de antagônicas interpretações visa exatamente impedir a discricionariedade total do Judiciário na aplicação

\footnotetext{
${ }^{6}$ Conforme ensinado por Appio (2011, p. 41, 85 e 144), o Supremo assume neste particular "uma posição prospectiva, e não retrospectiva, como de regra ocorre", nas ações diretas de inconstitucionalidade, ressalvando "os efeitos sociais que reputa benéficos à sociedade". Sobre o assunto, cf. também SAMPAIO, 2002, p. 233-42.

${ }^{7}$ Para uma consulta sobre decisões nas quais o Supremo valeu-se de restrições constitucionais expressas e não expressas, cf. SILVEIRA, 2007, p. 18-25 (monografia).

${ }^{8}$ O próprio Gilmar Mendes (1990, p. 286-7) sustenta ser praticamente impossível delimitar as diferenças entre os dois institutos. Entretanto, em obra posterior (Id., 1996, p. 196-7), o mesmo autor adota entendimento divergente, considerando necessário que se tente firmar sua distinção dogmática, no sentido acima explicitado (Id., Apud HEINEN, 2009, p. 3).
} 
dessa técnica. No entanto, isso não é tão facilmente definido. Segundo Appio (2011, p. 45-6), "todos os textos jurídicos apresentam diversas vias interpretativas", o que amplia problematicamente a liberdade do intérprete. Neste contorno - explica o citado autor coloca-se o debate entre a "corrente subjetivista" e a "corrente objetivista". Para a primeira, deve ser observada a "vontade do legislador"; para a segunda, "o legislador pode ter editado uma lei com outra finalidade, tendo produzido efeitos (válidos) não desejados", dando margem à reformulação do seu âmbito de aplicação.

O desenvolvimento da doutrina do controle de constitucionalidade, na maior parte dos países democráticos, levou a uma prevalência da concepção objetivista, que, como acima exposto, atribui autonomia ao texto legal em relação à vontade subjetiva daquele que o elaborou. Desse modo, o alcance da interpretação pela conformidade chega ao ponto de possibilitar "o controle da gênese legislativa", sendo aceitável que o intérprete avalie se o legislador, ao elaborar os textos legais, considerou os "dados empíricos disponíveis", a “experiência social” e o "interesse público" (SAMPAIO, 2002, p. 67-8).

No "domínio dos direitos, liberdades e garantias" o legislador vincula-se absolutamente aos preceitos constitucionais, o que "não admite exceções" (MIRANDA, 1993, p. 280). Por isso, os limites que normalmente são impostos pela doutrina à ação da jurisdição constitucional não se aplicam àqueles direitos; ou seja, em caso de simples ameaça de serem violados pela ação do Estado ou de terceiros, não se questiona a legitimidade da Suprema Corte em seu extenso poder revisional.

Daí a controvérsia que se apresenta, no mundo jurídico, acerca da atuação do Poder Judiciário como legislador positivo, o que ocorreria quando a interpretação conformadora terminasse por produzir uma alteração no texto legal. Quanto a isso, na grande maioria dos acórdãos proferidos pelo Supremo Tribunal Federal, nos quais se utilizou a técnica da interpretação conforme a Constituição, os ministros posicionam-se no sentido de que suas decisões interpretativas, ainda que importem em certo nível de alteração da norma-texto, não ferem o princípio da separação dos poderes ${ }^{9}$.

O Poder Jurisdicional tem que se preservar contra a alegação de que possa estar invadindo a esfera de atuação do Legislativo. Para isso, sustenta que é sempre melhor "salvar" a lei do decreto de inconstitucionalidade, presumindo sua constitucionalidade, pois, assim procedendo, estará mantendo a vigência da norma como formulada pelo legislador, embora com uma restrição interpretativa. A presunção da constitucionalidade das leis não deixa de

\footnotetext{
${ }^{9}$ Cf. SILVEIRA, op. cit., p. 39-49.
} 
representar um argumento simplista, já que o respeito ao conteúdo da lei "pode ser um mero pretexto para uma 'correção legislativa' por parte do Judiciário" (SILVA, 2006, p. 197-8). A fragilidade do argumento manifesta-se ainda mais quando se pensa no controle das leis anteriores à Constituição, eis que nesta hipótese não se pode presumir sua constitucionalidade porque foram elaboradas no contexto de uma ordem constitucional não mais em vigência. É preciso então encontrar outro fundamento que legitime a técnica, não sendo suficiente apoiarse na conveniência do respeito à obra do legislador.

No que concerne ao direito pré-constitucional, pode-se dizer que o fundamento jurídico-metodológico da interpretação pela conformidade é a necessidade de adequação do direito ordinário às mudanças ocorridas no mundo concreto, nas dimensões econômica, social e valorativa. Antes da edição das Leis 9868/99 e 9882/99, já mencionadas, o poder revisional do Supremo Tribunal no exame das leis anteriores à Constituição era muito mais restrito, e até vedado, em matéria pré-constitucional. A positivação da discricionariedade na conformação do ordenamento jurídico por intermédio do controle de constitucionalidade veio a atender justamente as crescentes demandas sociais afetas ao reconhecimento de direitos e ao processo de contextualização da norma. Se nesse amplo campo de atuação o Judiciário por vezes assume o papel de legislador positivo, fá-lo de modo a ampliar igualmente, no mesmo passo, a efetivação dos direitos individuais, coletivos ou sociais.

\section{O CABIMENTO DA AÇÃO DE DESCUMPRIMENTO DE PRECEITO FUNDAMENTAL NO CONTROLE DE LEIS OU ATOS NORMATIVOS}

A Lei 9882/1999 disciplinou a arguição de descumprimento de preceito fundamental, prevista no artigo 102, $\S 1^{\circ}$, da Constituição Federal. Trata-se de instrumento de controle de constitucionalidade especificamente centrado na concretização dos preceitos fundamentais. A primeira questão discutida, desde sua criação, é exatamente como definir o conteúdo hermenêutico do termo preceito fundamental ${ }^{10}$. Em relação aos direitos e garantias individuais, enfoque primordial do presente estudo, não há qualquer discussão, sendo inegável que se inserem na categoria normativa sob o alcance da arguição. Todavia, considerando o caráter abstrato desses direitos, é recorrente a presença de divergências no tocante ao seu efetivo âmbito de proteção.

10 Sobre a diferenciação terminológica entre os conceitos de regras, preceitos, princípios e valores constitucionais, cf. TAVARES, 2001, p. 106-26. 
O controle de constitucionalidade transformou-se, "a partir da obra pioneira de Capelletti", na "jurisdição constitucional das liberdades". Na mesma linha de pensamento, Enterrìa (apud TAVARES, 2001, p. 148-9. Grifo do autor) assim se expressa: "a liberdade é preferivel ou preferencial em relação a outros valores”. Desse modo, todos os preceitos constitucionais relacionados às liberdades, especialmente as mais básicas (liberdade de pensamento, de consciência/crença e de expressão), estão acobertados pela ADPF, quando descumpridos. Saliente-se que o conceito de descumprimento aqui não significa "apenas a não-observância", mas também "a não-execução" das prescrições dotadas do estatuto de fundamentalidade (TAVARES, 2001, p. 166).

Pelo teor dos artigos $1^{\circ}$, caput, e $3^{\circ}$, ambos da Lei 9882/1999, o requisito essencial para a propositura da arguição é a evidência de ameaça ou "lesão a preceito fundamental, resultante de ato do poder público". No artigo $1^{\circ}, \S$ único, está previsto que a ação também é cabível quando for "relevante o fundamento da controvérsia constitucional sobre lei ou ato normativo". Entende-se que o caput do artigo $1^{\text {o }}$ trata da arguição autônoma - controle concentrado - e que seu parágrafo único trata da arguição incidental - controle difuso. A primeira espécie direciona-se a qualquer ato do poder público, e a segunda espécie direcionase apenas às leis ou aos atos normativos (BARROSO, 2011, p. 302-4).

No que diz respeito à ação declaratória de constitucionalidade, a jurisprudência do Supremo consagrou o entendimento de que sua propositura somente é legítima se for demonstrada a relevância da controvérsia sobre a validade do ato normativo impugnado. Além disso, adotou-se a tese de que essa controvérsia tem que ser judicial, ou seja, é necessário que "órgãos jurisdicionais diversos" tenham se pronunciado de forma contrária no que diz respeito à constitucionalidade daquele ato (ADC 1, cf. MENDES, 2011, p. 174). A questão foi assim definida em face de disposição expressa contida na Lei 9868/99 (artigo 14) determinando que a existência da controvérsia judicial seja indicada já na petição inicial para a admissibilidade da ação em comento.

Sustenta Gilmar Mendes (2011, p. 174) que "essa orientação deve ser estendida à ADPF, especialmente àquela de perfil incidental". A ação de perfil incidental seria justamente aquela cujo objeto já tenha sido tema de controvérsia judicial em sede de controle concreto de constitucionalidade. Observe-se que o artigo $3^{\circ}$ da Lei 9882/1999 assim dispõe: "se for $o$ caso", a controvérsia deve ser comprovada na petição inicial da ADPF (grifo nosso), o que dá margem ao estabelecimento de uma particularidade distintiva nos requisitos de admissibilidade da ADPF autônoma em relação àqueles exigidos para a ação declaratória de constitucionalidade. Quer dizer, a lei exige a prova da controvérsia somente na hipótese da 
arguição incidental, e não na hipótese da autônoma ${ }^{11}$. Não há impedimento a que a ADPF assuma características peculiares que a distinga das demais ações declaratórias de controle concentrado, pressupondo-se cuidar-se de um instituto independente e dotado de finalidade própria.

Gilmar Mendes (2011) considera, inclusive, que a exigência de controvérsia judicial restringe sobremaneira o cabimento da própria propositura da ação declaratória de constitucionalidade. Maior seria essa restrição se a mesma exigência fosse feita no tocante à ADPF autônoma, cuja ratio essendi é a ampliação da salvaguarda dos direitos fundamentais e do acesso dos cidadãos aos tribunais superiores na defesa desses direitos. Lembre-se de que a ADPF é a única via que possibilita a revisão judicial do direito pré-constitucional; portanto, deve-se assegurar ao máximo seu campo de validade, impondo-se apenas as restrições necessárias.

O "acesso de qualquer cidadão à arguição", previsto no texto original da Lei 9882/1999 (artigo $2^{\circ}$ ) foi objeto de veto presidencial. Esse veto, segundo a doutrina, foi um equívoco, já que a ADPF "não é um recurso", e sim uma forma de provocação imediata do Supremo $^{12}$, o que, em tese, pode ocorrer tanto “por via de ação como por via de exceção". Na segunda hipótese - via de exceção - a arguição seria proposta no bojo de um caso concreto, na qualidade de uma ação "de caráter difuso" que, depois de admitida, passaria "a gerar o controle concentrado" de constitucionalidade (TAVARES, 2001, p. 395-7 e 406).

Diante do veto, a única alternativa à disposição do cidadão é a prevista no artigo $2^{\circ}, \S$ $1^{\text {o }}$ da Lei 9882/1999, isto é, representar ao Procurador-Geral da República, solicitando-lhe a propositura da arguição. André Tavares (2001, p. 407-8) afirma ser exigência da lei que o interessado proponha antes uma ação judicial (arguição incidental) que sirva de fundamento para sua representação ao Procurador-Geral. Isso porque, de acordo com o dispositivo citado, o Procurador, ao receber a representação, deverá avaliar "os fundamentos jurídicos do pedido", sendo essa uma "terminologia própria do campo processual". Logo, a letra da lei estaria impondo uma prévia ação nas vias ordinárias na qual fosse levantado o

\footnotetext{
${ }^{11}$ O STF já teve a oportunidade de delinear esse aspecto na ADPF 153 (BRASIL, 2010), referente à impugnação de dispositivo da Lei 6683/1979 (Lei da anistia).

12 Lenio Streck (2001, p. 265-6), por exemplo, defende a inconstitucionalidade desse veto presidencial, considerando que a ADPF foi concebida originalmente pelo legislador constituinte como um "mecanismo supletivo de acesso à jurisdição constitucional", disponibilizado aos cidadãos. Entende o autor que essa inconstitucionalidade pode ser declarada por meio da técnica da interpretação conforme a Constituição.
} 
descumprimento de um preceito fundamental em espécie. O interessado simplesmente optaria por representar ao Procurador-Geral, em vez de apresentar "a arguição incidental". 13

Em princípio, arrisca-se propor que não há razão para a necessidade de interposição prévia de ação judicial para que o Procurador-Geral maneje a ADPF autônoma a pedido do interessado. Por certo, veicula-se neste tipo de arguição um interesse individual ou coletivo específico. Porém, o conhecimento da ação dependerá da relevância do preceito descumprido do ponto de vista do "ordenamento constitucional objetivo" (MENDES, 2011, p. 182). O descumprimento só é relevante o bastante para justificar a arguição autônoma quando "o seu deslinde tiver uma repercussão geral”, que vá além da pretensão do interessado. Dimensionase o interesse público ou em decorrência de controvérsia interpretativa judicialmente manifestada ou em decorrência "da fundamentalidade" dos argumentos em exame, "por seu alcance político, econômico, social ou ético" (BARROSO, 2011, p. 318). Assim, o que deve ser sopesado é o grau de envolvimento de questões de interesse geral em discussão, considerando inclusive a realidade fática em matéria de desatendimento do preceito fundamental, e não necessariamente a existência de controvérsia hermenêutica no plano do processo judicial.

Com essa interpretação, sugere-se que o artigo $2^{\circ}$, $\S 1^{\circ}$, da Lei $9882 / 1999$, ao prescrever que o Procurador-Geral examinará “os fundamentos jurídicos do pedido”, a fim de formar sua convicção no sentido de propor ou não a ADPF, está se referindo aos fundamentos do pedido exposto na representação que o interessado lhe dirigiu. Essa seria uma maneira legítima de facilitar o acesso individual às vias de controle concentrado de constitucionalidade, em caso de descumprimento de preceito fundamental. Não se trata de uma interpretação incoerente, uma vez que a ADPF interposta pelo Procurador, in casu, é de natureza autônoma, e não incidental, inexistindo fundamento para se exigir prova de controvérsia judicial prévia.

\section{CONCLUSÃO}

A controvérsia em torno do caráter legislativo das decisões do Supremo Tribunal Federal, em que pese toda a problemática nela envolvida em matéria de legitimidade, é

\footnotetext{
${ }^{13}$ Luís Barroso (2011, p. 304-5) salienta que a via incidental "tornou-se muito limitada" após o citado veto presidencial. Os legitimados para apresentar a ação incidental são os mesmos previstos para a ação autônoma. Logo, "não se vislumbra por qual razão não optariam pela via autônoma, cujos requisitos são menos rígidos". No $\mathrm{STF}$, "os reais contornos da modalidade incidental" acabaram caindo no "quase esquecimento em face das hipóteses de cabimento mais amplas da ADPF autônoma".
} 
bastante produtiva no cenário político-jurídico do país. Chama-se a atenção para a necessidade da aplicação dos princípios constitucionais na resolução das demandas concretas levadas às autoridades públicas. A flagrante situação de ausência da execução efetiva das garantias individuais e coletivas, derivada da não atualização do direito pré-constitucional, termina por colocar o Poder Judiciário na posição de protagonista da recriação do próprio ordenamento jurídico.

Por um lado, o Supremo Tribunal não se afasta do perfil legalista, na medida em que considera admissível não propriamente a mudança da norma originária, mas a modulação dos seus efeitos no juízo de aplicação. Por outro lado, avança no conteúdo dessa modulação, com fundamento nas técnicas interpretativas de materialização do direito justo, o que tem trazido importantes conquistas sob a perspectiva das expectativas sociais. Como um reflexo desse movimento, ressurge igualmente uma abertura institucional para o aumento da participação das autoridades públicas administrativas, que, por meio de suas políticas, desempenham tarefa complementar na concessão dos direitos salvaguardados pela Constituição Federal.

Defende-se, nessa sede, que as mudanças promovidas pelo Poder Judiciário, em termos de reconstrução do sistema normativo pré-constitucional, são legítimas, na medida em que derivam de uma discricionariedade conferida pelo legislador e, principalmente, porque se revelam compatíveis com os valores sociais do tempo presente. Embora algumas decisões tenham provocado certo nível de polêmica no espaço do debate público, em geral o que se observa é que a sociedade vem recepcionando com naturalidade as inovações introduzidas na interpretação das leis, numa demonstração de que elas não representam nenhum tipo de ameaça ao princípio da segurança jurídica.

A abrangência da jurisdição constitucional no Brasil está em um momento de reformulação, sendo que os mecanismos e instrumentos procedimentais para o seu exercício demandam ainda um amadurecimento teórico-jurídico alcançável na própria prática de julgamento das ações de controle de constitucionalidade. Mas já é notável o nível de acolhimento da validade da revisão judicial de atos do poder público na esfera da garantia das liberdades individuais e dos direitos a elas conexos, na medida em que se consolida a utilização de decisões interpretativas.

\section{REFERÊNCIAS}

APPIO, Eduardo Fernando. Interpretação conforme a constituição. Instrumentos de Tutela Jurisdicional dos Direitos Fundamentais. Curitiba: Juruá, 2011. 
BARROSO, Luís Roberto. O Controle de constitucionalidade no direito brasileiro. São Paulo: Saraiva, 2011.

BRASIL. Constituição da República Federativa do Brasil de 1988. Diário Oficial da República Federativa do Brasil, Brasília, DF, 05 out 1988. Disponível em: $<$ http://www.planalto.gov.br/ccivil_03/constituicao/Constituicao.htm>. Acesso em: 01 maio 2014.

. Lei $\mathrm{n}^{\mathrm{o}}$ 9868, de 10 de novembro de 1999. Dispõe sobre o processo e julgamento da ação direta de inconstitucionalidade e da ação declaratória de constitucionalidade perante o Supremo Tribunal Federal. Diário Oficial da União, Brasília, DF, 11 nov. 1999. Disponível em: <http://www.planalto.gov.br/ccivil_03/leis/19868.htm>. Acesso em: 01 maio 2014.

Lei $\mathrm{n}^{\circ}$ 9882, de 03 de dezembro de 1999. Dispõe sobre o processo e julgamento da argüição de descumprimento de preceito fundamental, nos termos do $\S 1$ o do art. 102 da Constituição Federal. Diário Oficial da União, Brasília, DF, 06 dez. 1999. Disponível em: $<$ http://www.planalto.gov.br/ccivil_03/leis/19882.htm>. Acesso em: 01 maio 2014.

. Supremo Tribunal Federal. Tribunal Pleno. Arguição de descumprimento de preceito fundamental 153 Distrito Federal, de 21 out. 2008. Questiona a vigência dos artigos $1^{\circ}$ e $\S 1^{\circ}$ da Lei 6683/1979 ante a nova ordem constitucional de 1988. Relator: Ministro Eros Grau. Acórdão: $29 \quad$ abr. 2010.2 Disponível $<$ http://www.stf.jus.br/arquivo/cms/noticianoticiastf/anexo/adpf153.pdf $>$. Acesso em: 01 maio 2014.

. Supremo Tribunal Federal. Súmula $n^{\circ}$ 266. Não cabe Mandado de Segurança contra lei em tese. Sessão Plenária de 13/12/1963. Disponível em : $<$ http://www.stf.jus.br/portal/jurisprudencia/listarJurisprudencia.asp?s1=266.NUME.\%20NA O\%20S.FLSV.\&base=baseSumulas $>$. Acesso em: 01 maio 2014.

CANOTILHO, J. J. Gomes. Direito constitucional e teoria constitucional. $3^{\mathrm{a}}$ edição. Coimbra: Livraria Almedina, 1999.

COLNAGO, Cláudio de Oliveira Santos. Interpretação conforme a constituição: decisões interpretativas do STF em sede de controle de constitucionalidade. Coleção professor Gilmar Mendes. São Paulo: Método, 2007.

DWORKIN, Ronald. Justice in Robes. London: Harvard University Press, 2006.

ELY, John Hart. Democracy and distrust. A theory of judicial review. Cambridge: Harvard University Press, 1980.

FALCONE, Marconi. Justiça Constitucional: o caráter jurídico-político das decisões do STF. Coleção professor Gilmar Mentes. São Paulo: Método, 2009.

HEINEN, Juliano. Diferenças entre o instituto da interpretação conforme a constituição e a declaração de inconstitucionalidade parcial sem redução de texto. 2009. Disponível em $<$ http://www.esapergs.org.br/site/ arquivos/tese 1299781315.pdf>. Acesso em: 28 ago. 2012. 
MENDES, Gilmar Ferreira. Arguição de descumprimento de preceito fundamental. $2^{\mathrm{a}}$ edição. São Paulo: Saraiva, 2011.

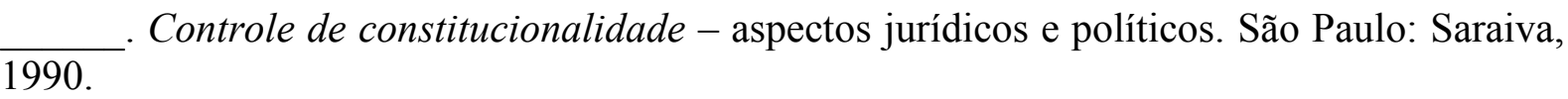
Direitos fundamentais e controle de constitucionalidade. $3^{\text {a }}$ edição. São Paulo: Saraiva, 2009.

. Jurisdição constitucional. São Paulo: Saraiva, 1996.

MIRANDA, Jorge. Manual de direito constitucional. T. IV. Coimbra: Coimbra Editora, 1993.

PERRY, M. J. The constitution in the courts. Law or Politics? New York: Oxford University Press, 1994.

ROSENFELD, Michel. The identity of the constitutional subject. London: Routledge, 2010.

SAMPAIO, José Adércio Leite. A Constituição reinventada pela jurisdição constitucional, Belo Horizonte: Del Rey, 2002.

SARLET, Ingo Wolfgang. A eficácia dos direitos fundamentais. Porto Alegre: Livraria do Advogado, 2007.

SILVA, Virgílio Afonso da. Interpretação conforme a constituição: entre a trivialidade e a centralização judicial. Revista Direito GV 3, v. 2, n. 1, jan-jun/2006, p. 191-210. Disponível em <http://direitogv.fgv.br/sites/direitogv.fgv.br/files/rdgv_03_p191_210.pdf>. Acesso em: 30 ago. 2012.

SILVEIRA, Leonardo de Aguiar. A interpretação conforme a constituição permite a alteração de normas? São Paulo, 2007. Disponível em $<$ http://www.sbdp.org.br/arquivos/material/266_Leonardo\%20de\%20Aguiar\%20Silveira.pdf $>$ . Acesso em: 28 ago. 2012.

STRECK, Lenio Luiz. Jurisdição constitucional e hermenêutica. $2^{\mathrm{a}}$ edição. Rio de Janeiro: Forense, 2004.

- Os meios de acesso do cidadão à jurisdição constitucional, a arguição de descumprimento de preceito fundamental e a crise de efetividade da constituição brasileira. In: Hermenêutica e Jurisdição Constitucional. José Adércio Leite Sampaio et al. (Coord.). Belo Horizonte: Del Rey, 2001, p. 249-94.

TAVARES, André Ramos. Tratado da arguição de preceito fundamental. São Paulo: Saraiva, 2001.

VIANNA, Luiz Werneck et al. A judicialização da política e das relações sociais no Brasil. Rio de Janeiro: Editora Revan,1999. 


\title{
INDIVIDUAL RIGHTS AND THE REVIEW OF BRAZILIAN PRE- CONSTITUTIONAL LAW IN THE SCOPE OF CONCENTRATED CONSTITUTIONAL REVIEW
}

\begin{abstract}
This paper investigates the updated techniques regarding the exercising of the concentrated control of constitutionality in the Brazilian system, on laws and norms enacted prior to the current Constitution. It will be shown how was built the admissibility of preconstitutional law review in the Supreme Court, and how the modulation mechanisms of judicial review brought a remarkable, productive procedural flexibility to the decision-making practice. The interpretation according to the constitution, particularly, is being improved as an instrument for the preservation of legal norms which are not entirely unconstitutional. Besides, it enables the necessary removal, from the legal system, of hypotheses that are deemed nonconforming to the principle-based constitutional provisions. In the same direction, the instrument called Claim of Breach of Fundamental Precept has been an important mean for the defense of the Constitution supremacy and for the effectiveness of individual freedoms therein guaranteed.
\end{abstract}

KEYWORDS: Breach of fundamental precept. Concentrated control. Constitutional interpretation. Constitutional jurisdiction. Pre-constitutional law. 